\title{
Comparison of energy consumption between non-inverter and inverter-type air conditioner in Saudi Arabia
}

\author{
Ahmed Almogbel ${ }^{1} \cdot$ Fahad Alkasmoul $^{1} \cdot$ Zaid Aldawsari $^{1}$ Jaber Alsulami ${ }^{1} \cdot$ Ahmed Alsuwailem $^{1}$
}

Received: 30 September 2020 / Accepted: 12 November 2020 / Published online: 7 December 2020

(c) The Author(s) 2020

\begin{abstract}
Interest for air-conditioning systems (ACs) has exponentially expanded worldwide throughout the most recent couple of decades. Countries with booming economies including Saudi Arabia report high growth of sales of room air conditioners. With the expanded (GDP) and warming climates, interest for room air-conditioning systems is required to additionally increment. Meeting the expanded need for electricity energy will be a challenge. Expanded utilization of energy-efficient air conditioners impactsly affects lowering the electricity demand. In an ordinary AC, the blower runs at a fixed speed and is either ON or OFF. In an inverter AC, the compressor is consistently on; however, power drawn relies upon the demand for cooling. The speed of the compressor is adjusted appropriately. In this paper, the energy consumption of non-inverter and an inverter $\mathrm{AC}$ of the same capacity was assessed in an average office room, under comparative operating conditions, to find the differences in the energy saving, Carbon Dioxide $\left(\mathrm{CO}_{2}\right)$ emission, and power consumption of air conditioner. Energy consumption was measured for about 108 days, which is from July 16th to October 31st, 24/7, and compared. The experiment is conducted with the same conditions and same capacity air conditioners (18,000 BTU). Results show that the day-by-day normal vitality utilization, the inverter will save up to $44 \%$ of electrical consumption compared to a non-inverter of $3471 \mathrm{kWh} /$ year and $6230 \mathrm{kWh} /$ year respectively. Furthermore, the Total Equivalent Warming Impact (TEWI) analysis shows that inverters can save $49 \%$ of $\mathrm{CO}_{2}$ emissions.
\end{abstract}

Keywords Air conditioner · Inverter AC · Energy efficiency $\cdot$ Carbon emission

\section{Introduction}

Around $52 \%$ of the electricity energy produced in Saudi Arabia is utilized in buildings and around $66 \%$ of that is utilized via air conditioners Alrashed and Asif [1, 2]. This is a consequence of the severe climatic conditions characterized, in

Ahmed Almogbel

aalmogbel@kact.edu.sa

Fahad Alkasmoul

fkassmoul@kacst.edu.sa

Zaid Aldawsari

zaldawsari@kacst.edu.sa

Jaber Alsulami

jalsulami@kacst.edu.sa

Ahmed Alsuwailem

abalsuwailem@kacst.edu.sa

1 Energy and Water Research Institute, King Abdulaziz City for Science and Technology, P.O. Box 6086, Riyadh 11442, Saudi Arabia general, by a long and hot summer. Expanding in population, increasing in advance plans, and keeping a low indoor temperature for buildings have played a vital role on increasing the demand of electricity for the last decades. In addition, due to the expanding rate of electricity and aggressive effect on the environment from power generation, it is necessary to find the means to seriously reduce energy consumption in buildings. Since the major part of the energy is consumed by cooling systems in buildings, reducing these consumption loads becomes most significant figures for energy conservation in buildings. Therefore, switching towards renewable energy resources and the progress of energy efficiency are the key factors to reduce energy consumption, thereby reducing the construction costs of generating plants and mitigating the global warming problem. One of the key technologies as a solution is inverter air conditioner.

The aim of using inverter air conditioners is reducing the energy consumption through controlling the frequency to meet the desired load while maintaining comfortable indoor conditions Ghosh and Mali [3]. However, installing inverter 
air conditioners adds extra cost compared to the non-inverter air conditioners. Nevertheless, this extra cost would be paid back in a "short" time by the savings made on the electricity bill Sukri and Jamali [4].

The inverter is an electronic controller that can drive electrical systems in smooth and efficient operation, especially for air-conditioning applications. The inverter air conditioner changes capacity freely by altering revolutions of the compressor. The inverter air conditioner can generate capacity corresponding to the load: when frequency is low, it generates low capacity with low revolutions, whereas when frequency is high, it generates high capacity with high revolutions. Non-inverter operates at fixed capacity, and the system is not designed to handle this variable load, but for the expected peak load. In an AC, the compressor is the component which consumes electricity. In non-inverter-type ACs, the compressor is either ON or OFF. When it is ON, it works at full capacity and uses the full amount of electricity it is designed to consume. When the set temperature in the $\mathrm{AC}$ is reached, the compressor is cut-off and cooling is stopped. When the thermostat senses that the room temperature has increased, the compressor switches ON again, automatically. That means, in normal air conditioners, the compressor is switched ON and OFF intermittently Ashvini et al [5].

The inverter-driven AC with varying cooling power has been studied over the last 2 decades and the well-known solution is to control the rotational speed of the compressor based on its cooling load. Nowadays, the inverter technology has proven its feasibility and competing the non-inverter.

The intense interest in the potential use of inverter air conditioners in buildings has resulted in the saving energy consumption being widely investigated. Many previous studies have reported anomalous conserves in electricity consumption compared with non-inverter air conditioners. Yurtseven et al. [6] carried out a field test analysis of inverter and non-inverter air conditioners to compare the energy saving in public offices in Istanbul. They found that the energy saving of the inverter air conditioners varies between 11 and $38 \%$ compared to and non-inverter air conditioners over the whole testing period and they also noticed that the inverter air conditioners is more energy efficient in the climate condition with high fluctuation temperature over a day. Ekala Jaela [7] compared the energy consumption of standard (non-inverter) and inverter air conditioners in an office building in Sri Lanka at the same capacity and similar environmental and operation conditions. It is found that the energy consumption of the inverter type is less about 35\% compared to non-inverter type. Rahul Khatri and Anant Joshi [8] investigated the effect of the ambient temperature on the performance of inverter and constant-speed air conditioners. They noticed that the inverter air conditioner saves more energy at partial load operation. It is also noticed that the inverter air conditioner is more efficient at long time operation and this result is the same conclusion was mentioned by Qiqi Zhang et al. [9]. A study on inverter and non-inverter air conditioner's performance in Riyadh and Seoul was conducted by Yoon et al. [10]. This study was performed in a precisely controlled air-tight style test room (outdoor side - temperature; indoor side - heat flow controlled) with a particular size and $26.0{ }^{\circ} \mathrm{C}$ air-conditioning temperature setting all day. Cooling period is 4 months in Korean and 9 months in Saudi Arabia Lim, et al [11]. Results show that inverter air conditioners are more energy efficient than noninverter air conditioners, even in a hot Saudi Arabian climate. The inverter-type saved energy from $18.3 \%$ to $47.1 \%$ was observed during the Riyadh cooling months, which are March-November, whereas, in Seoul, the energy saving was from $36.3 \%$ to $51.7 \%$ during Seoul cooling months, which are June to September.

Energy consumption in Saudi Arabia is fluctuating during the year. The annual report of Saudi Electricity Company (SEC) shows that electrical load is driven by temperature [12]. Therefore, this paper aims to investigate the energy consumption between inverter AC and non-inverter AC in Saudi climate in Jeddah during the summer season, as well as the environmental impact. A study of evaluating the payback period of inverter AC was conducted in Malaysia. The study shows that inverter AC with 50\% energy saving has a payback period of 4.67 years. However, energy saving can reach to $65 \%$ with dual human activity sensors, temperature waves, and sunlight sensors. The payback period is 3.42 years with energy saving of $65 \%$ Sukri and Jamali [4].

\section{Materials and methods}

This paper is conducted in the car maintenance office building at the Saudi Arabian Standards Organization (SASO) Jeddah, Saudi Arabia. There are two rooms for this analysis, and each room has the same dimension and is occupied by the same number of employees. The office area is $14.7 \mathrm{~m}^{2}$. Each room has three employees and it is considered as a

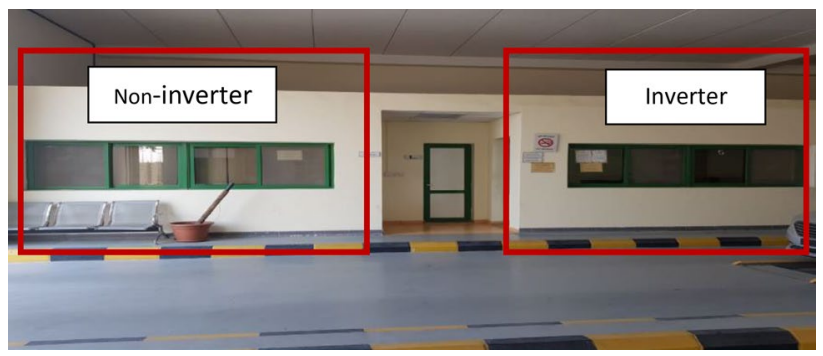

Fig. 1 Offices' front view 
normal employee office. Figure 1 indicates the front view of the rooms. The whole period of measurement is 108 days, which is from July 16th to October 31th, 24/7.
The comparison was conducted between two different units. One was an inverter unit with 1.50 tons, 13.35 Energy Efficiency ratio (EER) and refrigerant R32, as shown in
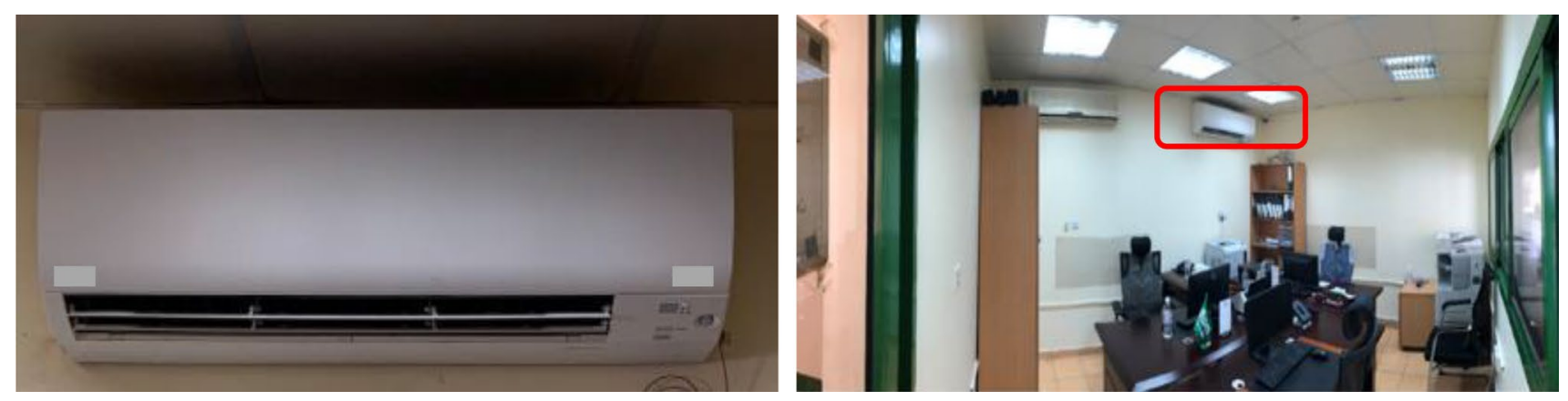

Fig. 2 Room of inverter unit
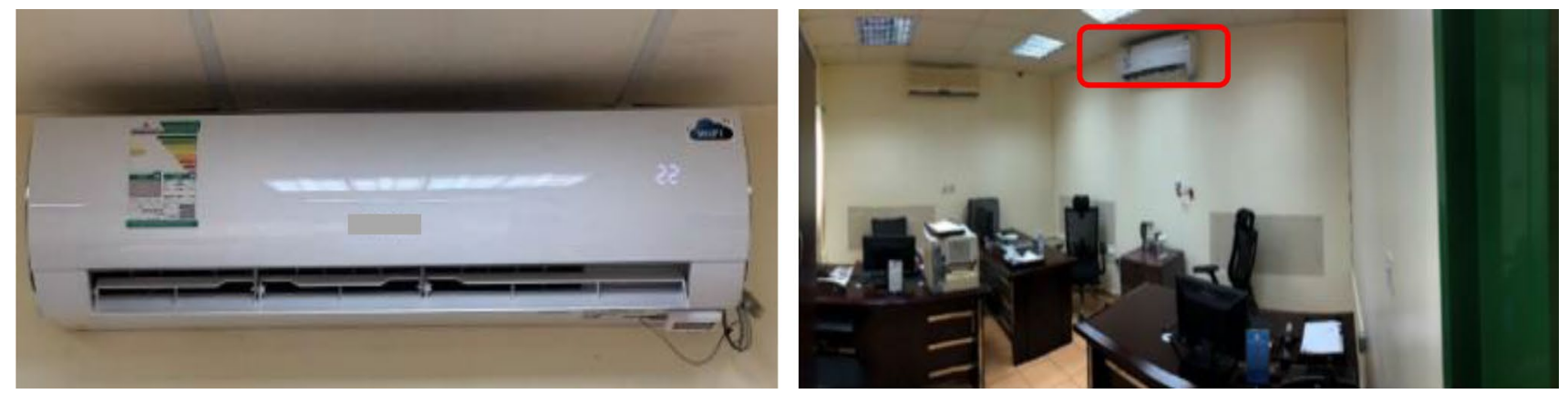

Fig. 3 Room of non-inverter unit

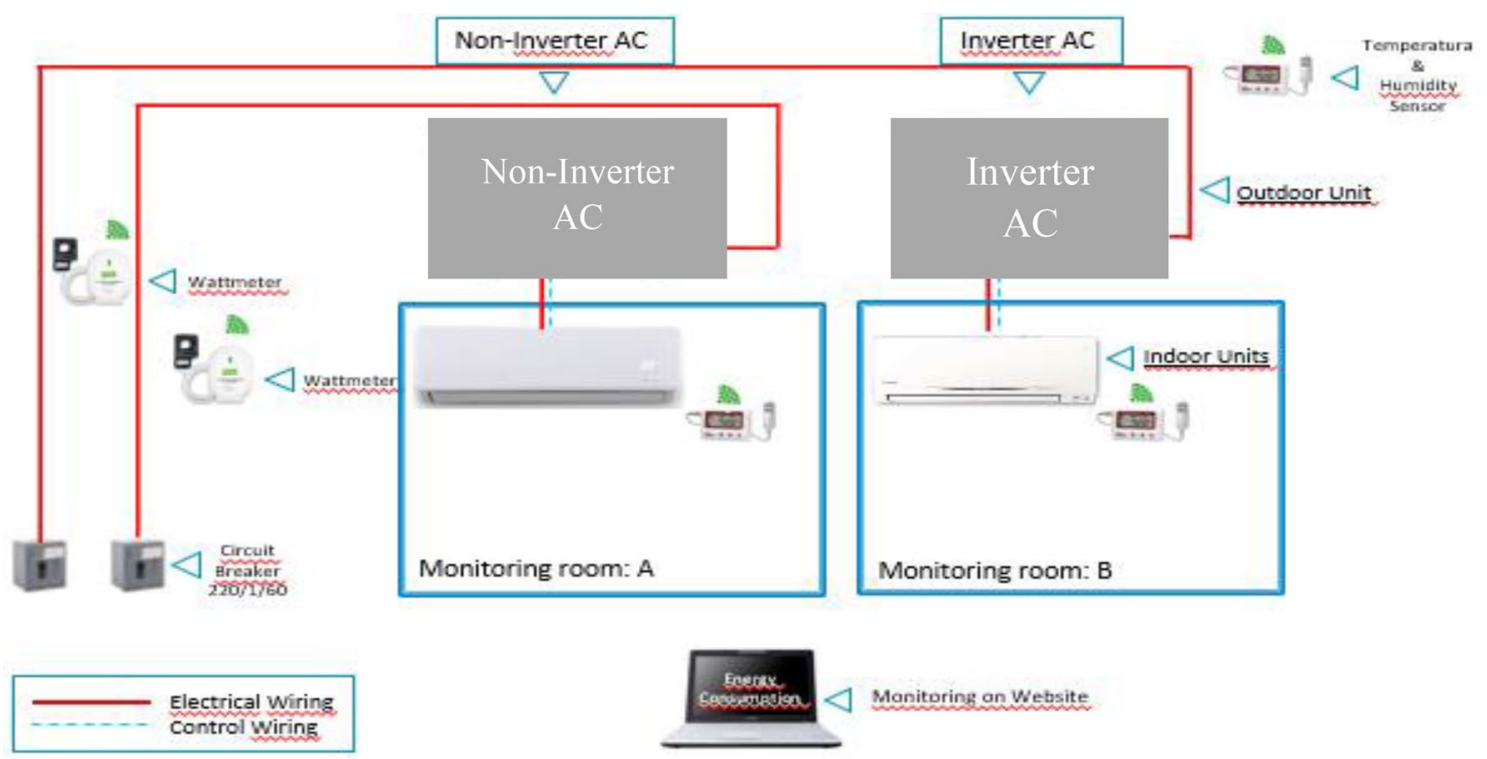

Fig. 4 Installed air conditionings and sensors 
Fig. 2. Another was non-inverter unit with 1.50 tons, 12.15 EER and refrigerant type R410a, as shown in Fig. 3 Both air conditioners were connected to the $220 \mathrm{~V} 60 \mathrm{~Hz}$.

Each room had two sensors mounted on the unit and on the wall to measure the temperature and humidity. In addition, there was one outdoor sensor to measure the temperature and humidity. Wattmeter was installed to record the energy consumption and to display it instantly in website. All these devices were mounted, as shown Fig. 4.

\section{Result}

\section{Energy saving analysis}

The test result analysis is divided into two parts for more details. The first part is Pattern A which is whole period of measurement from July 16 to October 31 (108 days). The second part is Pattern B, which is 18 days in a specific condition Alshahrani and Boait [13]. Under the condition, the average daily room temperature difference is $\pm 1{ }^{\circ} \mathrm{C}$. The setting temperature should have been kept between $22{ }^{\circ} \mathrm{C}$ and
$24{ }^{\circ} \mathrm{C}$ Al-Subhi and El-Amin [14]. However, the office users changed the set point of indoor temperature.

Figure 5 indicates the average daily energy consumption of Pattern A. Inverter AC's average energy consumption per day is $11.6 \mathrm{KWh} /$ day and non-inverter AC's is $20.8 \mathrm{KWh} /$ day. This means that the inverter AC's energy savings rate is around $44 \%$. The annual energy consumption is also calculated by this equation:

The average energy consumption per day $\times$ cooling Period

The cooling period in Jeddah city is assumed to be 300 days. Therefore, the inverter AC 's annual energy consumption is $3471 \mathrm{KWh} /$ year and the non-inverter AC's is $6230 \mathrm{KWh} /$ year.

For pattern B, Fig. 6 shows that the inverter average energy saving is $46 \%$ compared to non-inverter. In addition, the annual energy consumption for inverter will be 3068 $\mathrm{KWh} /$ year, whereas non-inverter is $5702.66 \mathrm{KWh} /$ year. On the other hand, Fig. 7 shows the graph on randomly selected typical days in July, August, September, and October. The idea for selecting random days is to see the behavior of the energy saving through the entire period. Thus, the figure
Fig. 5 Energy consumption for pattern $\mathrm{A}$

Fig. 6 Energy consumption for pattern B
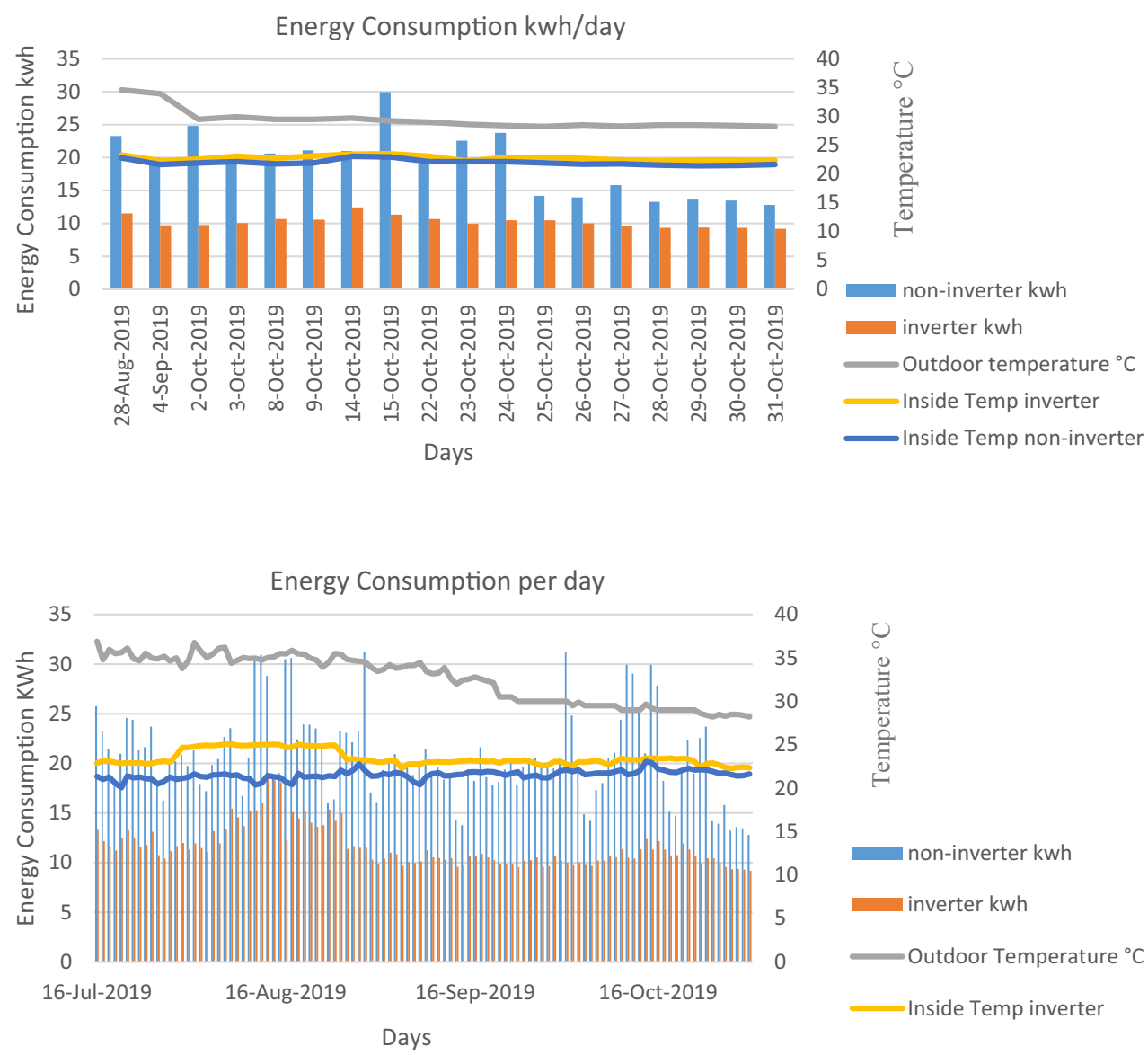
(a)

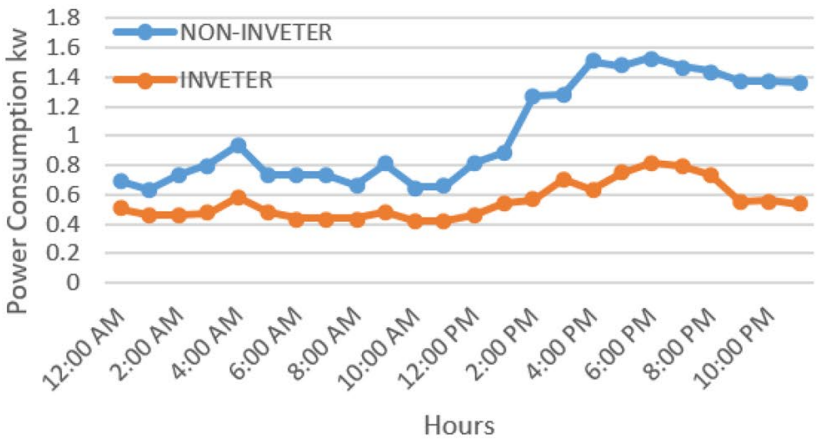

(c)

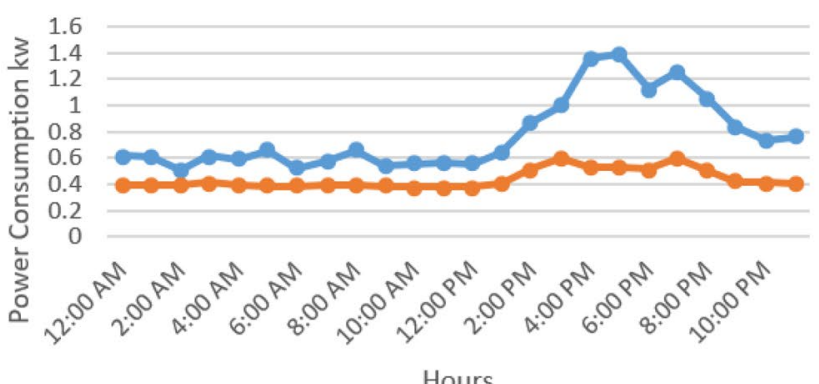

(b)

Aug 21, 2019

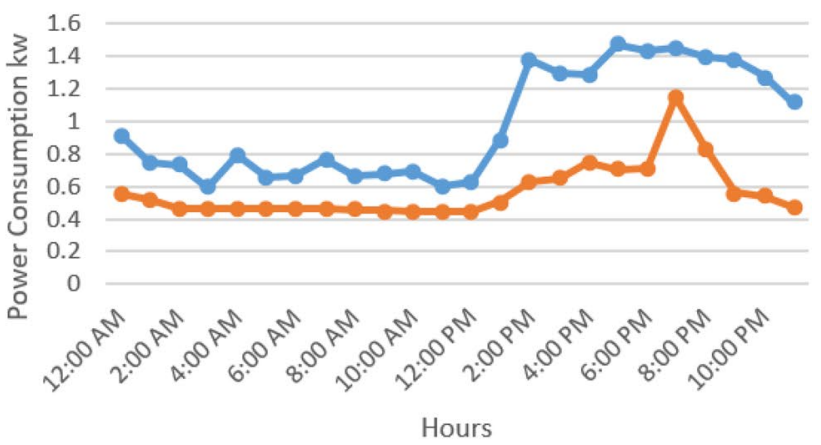

(d)

Oct 21, 2019

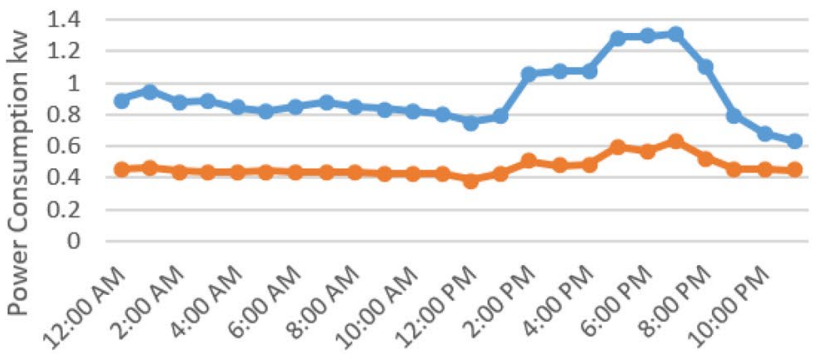

Hours

Fig. 7 Power consumption in randomly selected typical days: a July; b August; c September; d October

illustrates that the when the output temperature increases, the big difference between inverter and non-inverter appears on energy saving.

\section{$\mathrm{CO}_{2}$ emission reduction analysis}

Greenhouse Gas (GHG) including $\mathrm{CO}_{2}$ emission has become concern to the climate change. Although air conditioners contribute to a portion of these emissions, inverter technology can contribute to $\mathrm{CO}_{2}$ emission reduction. This paper will exam the difference between the inverter and non-inverter in term of $\mathrm{CO}_{2}$ emission.

First, there are two ways of greenhouse gas emissions (direct/indirect). The direct emission is the refrigerant released during the operation and at the end of life of AC. Indirect emission is the $\mathrm{CO}_{2}$ released due to producing electricity for operating $\mathrm{AC}$. To calculate the $\mathrm{CO}_{2}$ emission during AC's lifetime, the TEWI assessment for both inverter and non-inverter:

$$
\begin{aligned}
\text { TEWI }= & \frac{\text { GWP } \times \text { Charge }(\text { Leakrate } \times \text { Lifetime }+(1-\alpha))}{\text { Direct Emission }} \\
& +\frac{\text { Cosumption } \times \text { Emission factor } \times \text { Lifetime }}{\text { Indirect Emission (Electricity) }}
\end{aligned}
$$

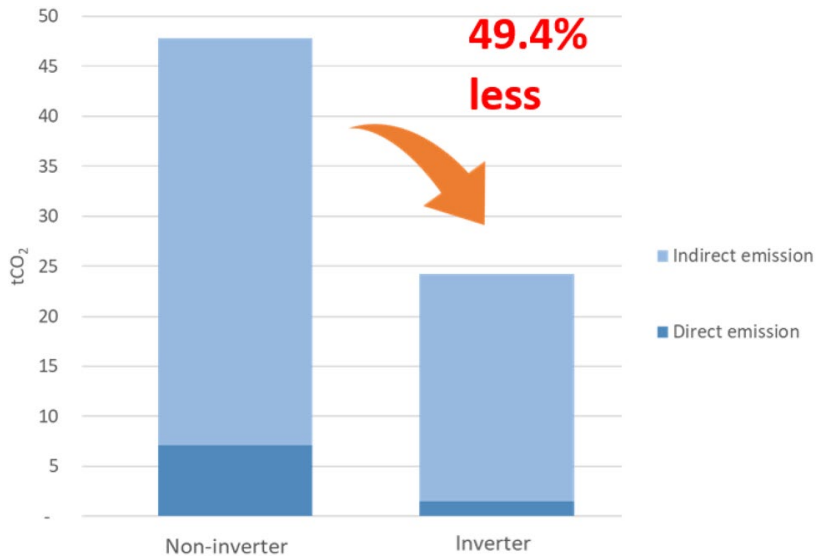

Fig. 8 Chart shows the TWEI result of inverter and non-inverter unit

Results show that the inverter R32 unit has less emission in both direct and indirect emissions than the noninverter R410A unit. Inverter R32 unit has less direct emission, because R32 unit has less GWP and less refrigerant charge than R410A. Also, inverter unit has less indirect emission, because it is more energy efficient than non-inverter unit. 
Table 1 Parameters required calculating TEWI for inverter (R32) and non-inverter (R410a)

\begin{tabular}{lllll}
\hline Parameter & Non-inverter & Inverter & Unit & Description \\
\hline Charge & 1.70 & 1.12 & $\mathrm{Kg}$ & Refrigerant charge \\
GWP & 2,088 & 675 & $\mathrm{kgCO}_{2} \mathrm{e} / \mathrm{kg}$ & Global warming potential \\
Leak rate & 10 & 10 & $\%$ & Annual leakage rate \\
Lifetime & 10 & 10 & Years & Period when AC is used \\
$\alpha$ & 0 & 0 & $\%$ & Refrigerant recovery rate at end of life \\
Consumption & 6,230 & 3,471 & $\mathrm{kWh}$ & Annual energy consumption \\
Emission factor & 0.654 & 0.654 & $\mathrm{kgCO}_{2} \mathrm{e} / \mathrm{kg}$ & Emission factor for Saudi Arabia \\
Direct emission & 7,099 & 1,512 & & \\
Indirect emission & 40,744 & 22,700 & & \\
TEWI & 47,843 & 24,212 & $\mathrm{kgCO}_{2} \mathrm{e} /$ lifetime & Total equivalent warming impact \\
\hline
\end{tabular}

*EF source: IGES-Version 10.6

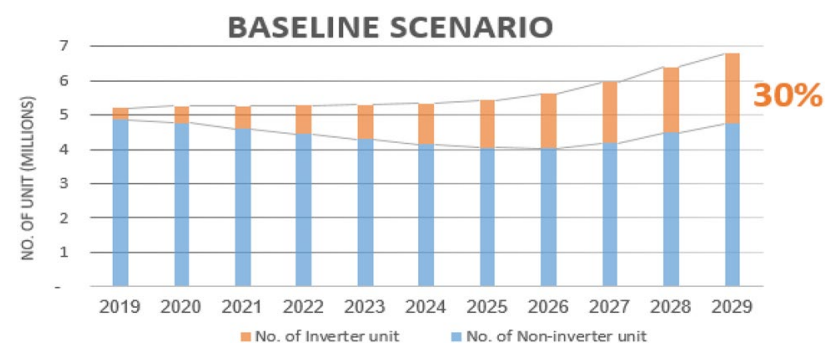

Fig. 9 Baseline:inverter ratio increases slightly (30\% in 2029)

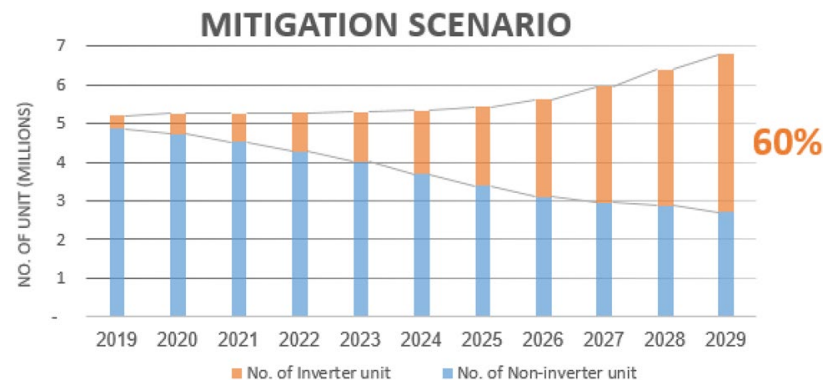

Fig. 10 Mitigation:inverter ratio increases rapidly (60\% in 2029)

Finally, the paper shows that the inverter R32 unit reduces the $\mathrm{CO}_{2}$ emission by $49.4 \%$ compared to noninverter R410A unit, as shown in Fig. 8.

We also estimate the GHG emissions difference in 2029 (in 10 years), comparing the baseline and mitigation scenario below:

GHG emissions difference $\left(\mathrm{t}-\mathrm{CO}_{2}\right)$ in 2029

$=$ TEWI result of Baseline scenario total stock

- TEWI result of Mitigation scenario total stock

where basline is the Performance Evaluation standard for air conditioners in Saudi Arabia with assumption to stay as EER
Table 2 Results of comparison

\begin{tabular}{lrr}
\hline Scenario & Total emissions of 10 years & Unit \\
\hline Baseline & $240,344,696$ & $\mathrm{t}-\mathrm{CO}_{2} \mathrm{e}$ \\
Mitigation & $222,790,083$ & $\mathrm{t}-\mathrm{CO}_{2} \mathrm{e}$ \\
Saving & $17,554,613 \mathrm{t}-\mathrm{CO}_{2} \mathrm{e}(7.3 \%)$ & \\
\hline
\end{tabular}

which stands for Energy Efficiency Ratio, and Mitigation is the standard in Saudi Arabia with assmuption to change to SEER which stands for Seasonal Energy Efficiency Ratio. Table 1 shows the parameters for both inverter and noninverter to calculaute the value of TEWI.

The results show that $17,554,613 \mathrm{t}-\mathrm{CO}_{2}$ could be saved if inverter $\mathrm{R} 32$ air conditioners are disseminated along with mitigation scenario compared to baseline scenario.

Figure 9 illustrates the baseline scenario for the next 10 years where the increment of the inverter units in 2029 is $30 \%$ from the baseline, while Fig. 10 shows the mitigation scenario of the inverter units with an increment in $60 \%$ from the baseline in 2029. Table 2 shows the result of this comparison which is saving about 7.3\% in $\mathrm{CO}_{2}$ emission in 2029.

\section{Conclusion}

This paper has been conducted with comparison between inverter and non-inverter air conditioner, which shows that the inverter can save energy consumption up to $44 \%$ compared to non-inverter with $3471 \mathrm{kWh} /$ year and $6230 \mathrm{kWh} /$ year, respectively. In addition, TEWI analysis demonstrates that inverter can save the $\mathrm{CO}_{2}$ emission by $49 \%$. The analysis clarifies the advantage of using air conditioners with inverter type instead of using non-inverter, especially for the weather in Saudi Arabia will reduce energy consumption. With the expected growth of AC use and ambient temperature rise due to global warming, inverter technology can provide 
significant savings. Moreover, due to the need for reducing greenhouse gases, the inverter type is more appropriate to decrease the $\mathrm{CO}_{2}$ emissions. Performance evaluation standard is a key factor to disseminating higher energy-efficient air conditioners. SEER reflects energy efficiency more accurately than EER and changing a standard from EER to SEER can lead to more energy efficient in KSA. Also, that will help consumers to understand the energy-saving impact of inverter $\mathrm{AC}$ and to raise their awareness of energy savings.

Acknowledgements This study was supported by the Ministry of Economy, Trade and Industry (METI), Government of Japan. Any opinions, finding, and conclusions expressed herein are those of the authors and are not necessary those of by METI there.

\section{Compliance with ethical standards}

Conflict of interest On behalf of all authors, the corresponding author states that there is no conflict of interest.

Open Access This article is licensed under a Creative Commons Attribution 4.0 International License, which permits use, sharing, adaptation, distribution and reproduction in any medium or format, as long as you give appropriate credit to the original author(s) and the source, provide a link to the Creative Commons licence, and indicate if changes were made. The images or other third party material in this article are included in the article's Creative Commons licence, unless indicated otherwise in a credit line to the material. If material is not included in the article's Creative Commons licence and your intended use is not permitted by statutory regulation or exceeds the permitted use, you will need to obtain permission directly from the copyright holder. To view a copy of this licence, visit http://creativecommons.org/licenses/by/4.0/.

\section{References}

1. Alaidroos, A., Krarti, M.: Optimal design of residential building envelope systems in the Kingdom of Saudi Arabia. Energy Build. 86, 104-117 (2015)

2. Alrashed, F., Asif, M.: Trends in residential energy consumption in Saudi Arabia with particular reference to the Eastern Province. J Sustain. Dev. Energy Water Environ. Syst. 2(4), 376-387 (2014). https://doi.org/10.13044/j.sdewes.2014.02.0030

3. Ghosh, A., Mali, K.V.: A review on DC inverter operated air conditioner. Int. J. Current Eng. Technol. 7, 306-309 (2017)
4. Sukri, M., Jamali, M.: Economics analysis of an inverter and noninverter typesplit unit air-conditioners for household application. J. Eng. Appl. Sci. 13(11) (2018)

5. Ashvini, G., Kamalsakthi, S., Baskaran, J.: PWM based active low power boost DC-AC inverter. In: 2017 International Conference on Computation of Power, Energy Information and Commuincation (ICCPEIC) (pp. 709-712). IEEE

6. Yurtseven, M, Erkin, E, Acuner, E, Mete, S, Onaygil, S: An experimental investigation of energy saving potentials for room type variable-speed air conditioners in public offices: a case study from Istanbul. Energy Build. 68, 165-171 (2014). https://doi.org/10.1016/j. enbuild.2013.09.020

7. Siriwardhana, M., Namal, D.A.: Comparison of Energy Consumption between a Standard Air Conditioner and an Inverter-type Air Conditioner Operating in an Office Building. SLEMA J 20(1-2) (2017)

8. Khatri, R., Joshi, A.: Energy performance comparison of inverter based variable refrigerant flow unitary $\mathrm{AC}$ with constant volume unitary AC. Energy Procedia 109, 18-16 (2016)

9. Zhang, Q., Guo, Q., Yu, Y.: Research on the load characteristics of inverter and constant speed air conditioner and the influence on distribution network. In: 2016 China International Conference on Electricity Distribution (CICED), pp. 1-4. IEEE

10. Yoon, M., Lim, J., Qahtani, T., Nam, Y.: Experimental study on comparison of energy consumption between constant and variable speed air-conditioners in two different climates. In: Proceedings of the 9th Asian Conference on Refrigeration and Air-conditioning (2018)

11. Lim, J, et al.: Feasibility study on variable-speed air conditioner under hot climate based on real-scale experiment and energy simulation. Energies 12(8), 1489 (2019)

12. Saudi Electricity annual report (2013) https://www.AnnualRepo rt2013En.pdf(se.com.sa)

13. Alshahrani, J., Boait, P.: Reducing high energy demand associated with air-conditioning needs in Saudi Arabia. Energies 12(1), 87 (2018)

14. Al-Subhi, A., El-Amin, I.: Experimental performance analysis of existing conventional $\mathrm{AC}$ air conditioner and corresponding new pure DC air conditioner. In: 2017 IEEE Second InternationalConference on DC Microgrids (ICDCM). (2017). https://doi.org/10.1109/ icdem.2017.8001065 